\title{
Impact of heterozygote CFTR Mutations in COPD patients with Chronic Bronchitis
}

\author{
S Vamsee Raju ${ }^{1,4,5}$, Jody H Tate ${ }^{1}$, Sandra KG Peacock ${ }^{6}$, Ping Fang ${ }^{6}$, Robert A Oster ${ }^{1}$, Mark T Dransfield ${ }^{1,4,5}$ \\ and Steven M Rowe $\mathrm{P}^{1,2,3,4,5^{*}}$
}

\begin{abstract}
Background: Cigarette smoking causes Chronic Obstructive Pulmonary Disease (COPD), the 3rd leading cause of death in the U.S. CFTR ion transport dysfunction has been implicated in COPD pathogenesis, and is associated with chronic bronchitis. However, susceptibility to smoke induced lung injury is variable and the underlying genetic contributors remain unclear. We hypothesized that presence of CFTR mutation heterozygosity may alter susceptibility to cigarette smoke induced CFTR dysfunction. Consequently, COPD patients with chronic bronchitis may have a higher rate of CFTR mutations compared to the general population.
\end{abstract}

Methods: Primary human bronchial epithelial cells derived from F508del CFTR heterozygotes and mice with (CFTR+/-) and without (CFTR+/+) CFTR heterozygosity were exposed to whole cigarette smoke (WCS); CFTR-dependent ion transport was assessed by Ussing chamber electrophysiology and nasal potential difference measurements, respectively. Caucasians with COPD and chronic bronchitis, age 40 to 80 with $\mathrm{FEV}_{1} / \mathrm{FVC}<0.70$ and $\mathrm{FEV}_{1}<60 \%$ predicted, were selected for genetic analysis from participants in the NIH COPD Clinical Research Network's Azithromycin for Prevention of Exacerbations of COPD in comparison to 32,900 Caucasian women who underwent prenatal genetic testing. Genetic analysis involved an allele-specific genotyping of 89 CFTR mutations.

Results: Exposure to WCS caused a pronounced reduction in CFTR activity in both CFTR (+/+) cells and F508del CFTR (+/-) cells; however, neither the degree of decrement (44.7\% wild-type vs. 53.5\% F508del heterozygous, $P=N S)$ nor the residual CFTR activity were altered by CFTR heterozygosity. Similarly, WCS caused a marked reduction in CFTR activity measured by NPD in both wild type and CFTR heterozygous mice, but the severity of decrement (91.1\% wild type vs. $47.7 \%$ CF heterozygous, $P=N S)$ and the residual activity were not significantly affected by CFTR genetic status. Five of 127 (3.9\%) COPD patients with chronic bronchitis were heterozygous for CFTR mutations which was not significantly different from controls (4.5\%) ( $P=N S)$.

Conclusions: The magnitude of WCS induced reductions in CFTR activity was not affected by the presence of CFTR mutation heterozygosity. CFTR mutations do not increase the risk of COPD with chronic bronchitis. CFTR dysfunction due to smoking is primarily an acquired phenomenon and is not affected by the presence of congenital CFTR mutations.

\section{Introduction}

Chronic obstructive pulmonary disease (COPD) is the 3rd leading cause of death in the U.S. and mortality is increasing [1]. An improved understanding of COPD pathogenesis, and the genes that contribute to its progression, are needed to develop therapeutic approaches

\footnotetext{
* Correspondence: smrowe@uab.edu

'Department of Medicine, University of Alabama at Birmingham, MCLM 706

1918 University Blvd., Birmingham, AL, USA

${ }^{2}$ Department of Pediatrics, University of Alabama at Birmingham,

Birmingham, AL, USA

Full list of author information is available at the end of the article
}

to the disease [2]. Susceptibility to lung injury from cigarette smoking is highly variable, with only $~ 15-20 \%$ of at risk individuals developing clinically significant COPD. While the presence of the $\mathrm{Z}$ allele of the alpha1 -antitrypsin (AAT) gene has been shown to increase the risk for COPD [3,4], it only accounts for a small fraction of cases. GWAS studies have not yet identified genetic contributors with a firm link to disease pathogenesis $[5,6]$. Complicating this further is the fact that the phenotypic expression of COPD is highly variable, with some individuals developing disease dominated by emphysema while others exhibit chronic bronchitis or 
both $[7,8]$ which likely reflects the contribution of multiple pathologic mechanisms.

There are more than 10 million Americans who are asymptomatic carriers of at least one CFTR mutation [9]. A number of disorders are associated with mild/variable CFTR mutations that cause intermediate phenotypic expression. For example, 30-50\% of patients with idiopathic pancreatitis are heterozygotes for CFTR mutations $[10,11]$, and a similar association has been made for congenital bilateral absence of the vas deferens [12] and allergic pulmonary aspergillosis [13]. We have previously reported that smokers with COPD have decreased CFTR function in both the upper [14] and lower airways [15], confirming prior studies in healthy smokers $[16,17]$ and suggesting that CFTR dysfunction may also play a role in the pathogenesis of COPD. CFTR dysfunction was also found to be associated with chronic bronchitis symptoms and dyspnea $[14,15]$, indicating CFTR abnormality may be particularly important towards causing mucus retention, and supports in vitro studies indicating reduced airway surface liquid depth $[14,17]$ and delayed mucociliary transport $[14,18]$ caused by cigarette smoke exposure. CFTR dysfunction has also been observed in mice exposed to whole cigarette smoke [19]. Since, a surprisingly large percentage of COPD patients have recently been found to have bronchiectasis by high resolution CT [20] and because chronic bronchitis shares many pathologic similarities with CF, it follows that genetic CFTR abnormalities may increase the prevalence of chronic bronchitis in smokers.

A previous study identified a moderate association between F508del CFTR mutations and in individuals with chronic bronchitis and sweat chloride levels of $60 \mathrm{mmol} / \mathrm{L}$ or higher [21]. Other studies demonstrating an association have been small and have not examined the frequency of CFTR mutations in COPD subtypes [22-24]. An association between common CFTR mutations and chronic bronchitis was not observed by Entzian et al. [25]. Similarly, earlier studies from Germany and Japan failed to detect an association between CFTR mutations and COPD [26,27], although neither focused on individuals with chronic bronchitis.

In this study, we hypothesized CFTR mutation heterozygosity would increase the susceptibility to cigarette smoke induced CFTR dysfunction. To our surprise, in vitro and in vivo studies revealed an absence of a gene-dose effect between cigarette smoking and CFTR dysfunction. This was further supported by the absence of increased CFTR mutation frequency in chronic bronchitis patients when compared to the general population. These findings indicate that CFTR dysfunction due to smoking is primarily an acquired phenomenon, and that CFTR mutations do not significantly increase the prevalence of acquired CFTR dysfunction induced chronic bronchitis.

\section{Methods}

\section{In vitro experiments with primary human airway} epithelial cells

UAB Institutional Review Board approved the use of human cells. Primary human bronchial epithelial cells (HBE) were obtained from lung explants. Genetic analysis was performed to identify cells with expression of wild type CFTR (CFTR $+/+$ ) and those heterozygous for nonfunctional (i.e. F508del) CFTR mutations (CFTR +/-) following previously described methods [28]. After expanding isolated HBE cells, first or second passage cells were seeded on permeable support filters (Corning, Lowell, MA) coated with NIH 3 T3 fibroblast conditioned media. HBE cells were grown in differentiating media for 6 weeks until terminally differentiated, as previously described [14].

HBE cells were exposed to WCS from one 3R4F research cigarette (University of Kentucky, Lexington, $\mathrm{KY}$ ) for $10 \mathrm{~min}$. WCS was generated via an automated cigarette smoke generator (Scireq InExpose model, Toronto, Canada) at $1 \mathrm{puff} / \mathrm{min}$ at a flow rate of $3 \mathrm{~L} / \mathrm{min}$, as previously described [19]. Controls cells were similarly exposed to room air.

CFTR-dependent short circuit current was measured in Ussing chambers under voltage clamp conditions using MC8 voltage clamps and P2300 Ussing chambers (Physiologic Instruments, San Diego, CA) [14]. CFTR activity was measured by the change in Isc upon stimulation with forskolin $(10 \mu \mathrm{M})$ in the setting of amiloride $(100 \mu \mathrm{M}) . \mathrm{A} \mathrm{Cl}^{-}$secretory gradient was used, where indicated; CFTR Inh $^{-172}(10 \mu \mathrm{M})$ was used to confirm CFTR dependence [29].

\section{In vivo cigarette smoke exposure}

Animal protocols were approved by the UAB Institutional Animal Care and Use Committee. Age and sex matched congenic C57BL/6 J mice expressing wild type CFTR $($ CFTR $+/+$ ) or heterozygous for CFTR knock out (CFTR +/-, C57BL/6 J Cftrtm1Unc/J) were used. Mice were exposed in whole-body chambers $\left(28^{\prime \prime} \times 19^{\prime \prime} \times\right.$ $\left.15^{\prime \prime}\right)$ to mainstream cigarette smoke $(200 \mu \mathrm{g} / \mathrm{l}$ of total particulate matter, $35-\mathrm{ml}$ puffs of 2 -s duration at a rate of $3 \mathrm{~L} / \mathrm{sec}$ each minute for $20 \mathrm{~min}$ ) from 4 3R4F reference cigarettes (Univ. of Kentucky, Lexington, KY) twice daily for 2 weeks using an automated cigarette smoking apparatus (SCIREQ, InExpose model, Toronto, Canada). Control mice were exposed to room air under similar conditions $[19,30]$.

\section{Measurement of murine CFTR activity}

Murine CFTR function was assessed by nasal potential difference measurements. Under anesthesia, CFTR-dependent anion transport was measured in the murine nasal epithelium as a change in potential difference following perfusion 
with chloride free forskolin $(10 \mu \mathrm{M})$ in the setting of amiloride $(100 \mu \mathrm{M})$, as previously described $[19,29]$.

Mice were euthanized and tracheas were harvested by clean surgical techniques. Tracheal epithelia were mounted and tested as full-thickness tissue. Isc was measured under voltage clamp conditions as performed in cells using P2307 Ussing chamber sliders. Mounted tissues were bathed on both sides with identical Ringers solutions gassed with $95 \% \mathrm{O}_{2}: 5 \% \mathrm{CO}_{2}$ and then treated with amiloride $(100 \mu \mathrm{M})$ followed by the CFTR agonists forskolin $(10 \mu \mathrm{M})$ and IBMX $(100 \mu \mathrm{M})$; bumetanide $(10 \mu \mathrm{M})$ and glybenclamide $(100 \mu \mathrm{M})$ were added to the mucosal solution at the end of experiments to block CFTR-dependent Isc. Results are expressed as the change in Isc with agonist stimulation [19,31].

\section{Genetic analysis of chronic bronchitis}

We performed a case control study to detect the prevalence of CFTR mutations in COPD patients with symptoms of chronic bronchitis. The UAB IRB approved use of clinical specimens for the research study. COPD cases were selected from participants in the NIH COPD Clinical Research Network's Azithormycin in COPD Study who had blood stored for genetic analysis [32]. Cases were non-Hispanic Caucasians, age 40 to 80 with $\mathrm{FEV}_{1}$ / $\mathrm{FVC}<0.70$ and $\mathrm{FEV}_{1}<60 \%$ predicted, and chronic bronchitis defined by productive cough "most days a week" or "several days of the week" on the St. George Respiratory Questionnaire (SGRQ). The control population was 32,900 Caucasian women who had CFTR analyzed for prenatal genetic testing, $\mathrm{N}=32,900$. No further demographic characteristics are available for this population.

DNA testing was performed by the Baylor College of Medicine Genetics Laboratory using a CFTR related disorders mutation panel. This is an allele-specific genotyping technique for 89 mutations (Table 1) performed by MALDI-TOF mass spectrometry and includes testing for mutations common in human populations and reflex testing of the $5 \mathrm{~T}$ allele. The method has an $88 \%$ CFTR mutation detection rate in the non-Hispanic Caucasian population. Additional data collected on COPD cases included age, sex, smoking status, smoking intensity (packyears), $\mathrm{FEV}_{1} \%$ predicted, and the number of COPD exacerbations requiring treatment in the year prior to enrollment in the azithromycin trial. The sample size of 127 patients had $80 \%$ power to detect a mutation rate in COPD patients of $10.5 \%$ as compared to a presumed frequency of $4.5 \%$ in controls with an alpha of 0.05 .

\section{Statistics}

For in vitro and in vivo studies, descriptive statistics (mean, SD, and SEM) were compared using Student's $t$-test or ANOVA, as appropriate. Post-hoc tests for multiple comparisons were calculated using Fisher's
Table 1 List of CFTR mutations analyzed

\begin{tabular}{|c|c|c|c|}
\hline F508del & $\mathrm{R} 117 \mathrm{H}$ & $1717-1 G>A$ & $\mathrm{R} 117 \mathrm{C}$ \\
\hline G85E & R334W & $1898+1 G>A$ & Y122X \\
\hline A455E & R347P & 2184delA & G178R \\
\hline 1507del & R553X & $2789+5 G>A$ & G314E \\
\hline G542X & R560T & $3120+1 G>A$ & G330X \\
\hline G551D & W1282X & 3659delC & $\mathrm{R} 347 \mathrm{H}$ \\
\hline N1303K & $621+1 G>T$ & K710X & $406-1 G>A$ \\
\hline R1162X & $711+1 G>T$ & E60X & G480C \\
\hline R1066C & W1089X & V520F & A559T \\
\hline S1196X & Q1238X & S1251N & S1255X \\
\hline 663delT & 935delA & 1161delC & 1288insTA \\
\hline 2184ins A & 2307insA & 2711delT & 2869insG \\
\hline R709X & $\mathrm{R} 764 \mathrm{X}$ & R1158X & 574delA \\
\hline Q493X & $1898+5 G>T$ & 3905ins T & I506T \\
\hline $3849+10 \mathrm{kbC}>\mathrm{T}$ & $712-1 G>T$ & Q98R & Q552X \\
\hline S549N & 1078delT & H199Y & 444delA \\
\hline S549R (T > G) & 2143delT & P205S & 2043delG \\
\hline $1811+1.6 \mathrm{kbA}>\mathrm{G}$ & $3272-26 A>G$ & L206W & 3791delC \\
\hline Y1092X (C> G) & 3199del6 & F508C & 2108delA \\
\hline Y1092X (C > A) & $\mathrm{D} 1152 \mathrm{H}$ & V520I & 3667del4 \\
\hline 394delTT & 3876delA & M1101K & 1677delTA \\
\hline W1098X (TGA) & $1812-1 G>A$ & 4016insT & 1609delCA \\
\hline $3171 \mathrm{delC}$ & & & \\
\hline
\end{tabular}

least significant difference. Population statistics were performed using SAS (IBM, Armonk, NY). Chi-square or Fischer's exact test used for inferential comparisons. All statistical tests were two-sided and were performed at a $5 \%$ significance level (i.e., $\alpha=0.05$ ) using GraphPad Prism (La Jolla, CA). Error bars designate SEM unless indicated otherwise.

\section{Results}

\section{Effect of CFTR mutation heterozygosity on smoke-} induced CFTR dysfunction in vitro

Since smokers with and without COPD exhibit reduced CFTR mediated anion transport [14-17,19], and this is associated with chronic bronchitis $[14,15,19]$, we hypothesized that acquired CFTR dysfunction may also be influenced by the presence of congenital CFTR mutations. As a test of this hypothesis, we exposed primary HBE cells heterozygous for the F508del CFTR mutation to whole cigarette smoke and compared this to the degree of CFTR decrement observed in HBE cells without CFTR mutations (e.g. wild-type expressing monolayers). As expected based on genotype-phenotype correlations in the disease [33], HBE cells derived from a F508del CFTR heterozygote had slightly lower CFTR activity at baseline than wild type monolayers as measured by 
response to forskolin stimulation $\left(49.3 \pm 11.5 \mu \mathrm{A} / \mathrm{cm}^{2}\right.$ in CFTR $(+/+)$ vs. $40.5 \pm 5.3 \mu \mathrm{A} / \mathrm{cm}^{2}$ in CFTR $(+/-)$, although this was not statistically significant (Figure $1 \mathrm{~A}, \mathrm{~B}$ ). WCS caused a pronounced reduction $\left(27.3 \pm 3.1 \mu \mathrm{A} / \mathrm{cm}^{2}\right)$ in CFTR activity in CFTR $(+/+)$ monolayers $(\mathrm{P}<0.05)$, consistent with prior studies using WCS $[17,19,30,34,35]$ and CSE $[14,36]$. WCS also caused a significant decrement in CFTR $(+/-)$ cells $\left(18.8 \pm 2.4 \mu \mathrm{A} / \mathrm{cm}^{2} ; \mathrm{P}<0.005\right)$. Both the relative decrement $(44.7 \%$ vs. $53.5 \%, \mathrm{P}<0.93)$ and the degree of residual CFTR activity in CFTR $(+/+)$ and CFTR $(+/-)$ cells following WCS exposure $\left(22.1 \pm 3.0 \mu \mathrm{A} / \mathrm{cm}^{2}\right.$ in CFTR +/+ vs. $21.6 \pm 3.8 \mu \mathrm{A} / \mathrm{cm}^{2}$ in CFTR +/-) was indistinguishable, indicating the presence of a single F508del CFTR mutation did not meaningfully alter the CFTR decrement from environmental exposure to WCS in vitro.

\section{Effect of CFTR mutation heterozygosity on smoke- induced CFTR dysfunction in vivo}

To better understand findings in human bronchial epithelial cells and provide definitive evidence regarding the contribution of heterozygous CFTR mutations to cigarette smoke induced CFTR dysfunction, we next used an animal model of cigarette smoke exposure. Congenic wild type $(\mathrm{CFTR}+/+)$ and heterozygote (CFTR +/-, C57BL/6 J Cftrtm1Unc/J) CF57BL/6 J mice were exposed in whole body chambers to cigarette smoke twice daily for 2 weeks, and then CFTR activity was measured in the respiratory tract by nasal potential difference (NPD) and short circuit current analysis of freshly excised trachea. As expected based on genotype-phenotype correlations in the disease, and observed in prior NPD studies in humans [33], NPD in heterozygote CFTR (+/-) mice had slightly lower CFTR activity when compared to the wild type mice $(-12.1 \pm 1.8 \mathrm{mV}$ in CFTR $(+/+)$ vs. $-8.7 \pm$ $0.6 \mathrm{mV}$ in CFTR $(+/-))$, although this was not statistically significant $(\mathrm{P}<0.14$, Figure 2$)$. Cigarette smoke exposure caused a significant decrease in CFTR-mediated ion transport in the nasal airway that was similar in severity to the observations in HBE cells (Figure 2). WCS caused a pronounced reduction $(-11.1 \mathrm{mV})$ in CFTR activity in CFTR $(+/+)$ mice $(\mathrm{P}<0.005)$, a finding recapitulated in CFTR $(+/-)$ mice $(-4.1 \mathrm{mV} ; \mathrm{P}<0.05)$.
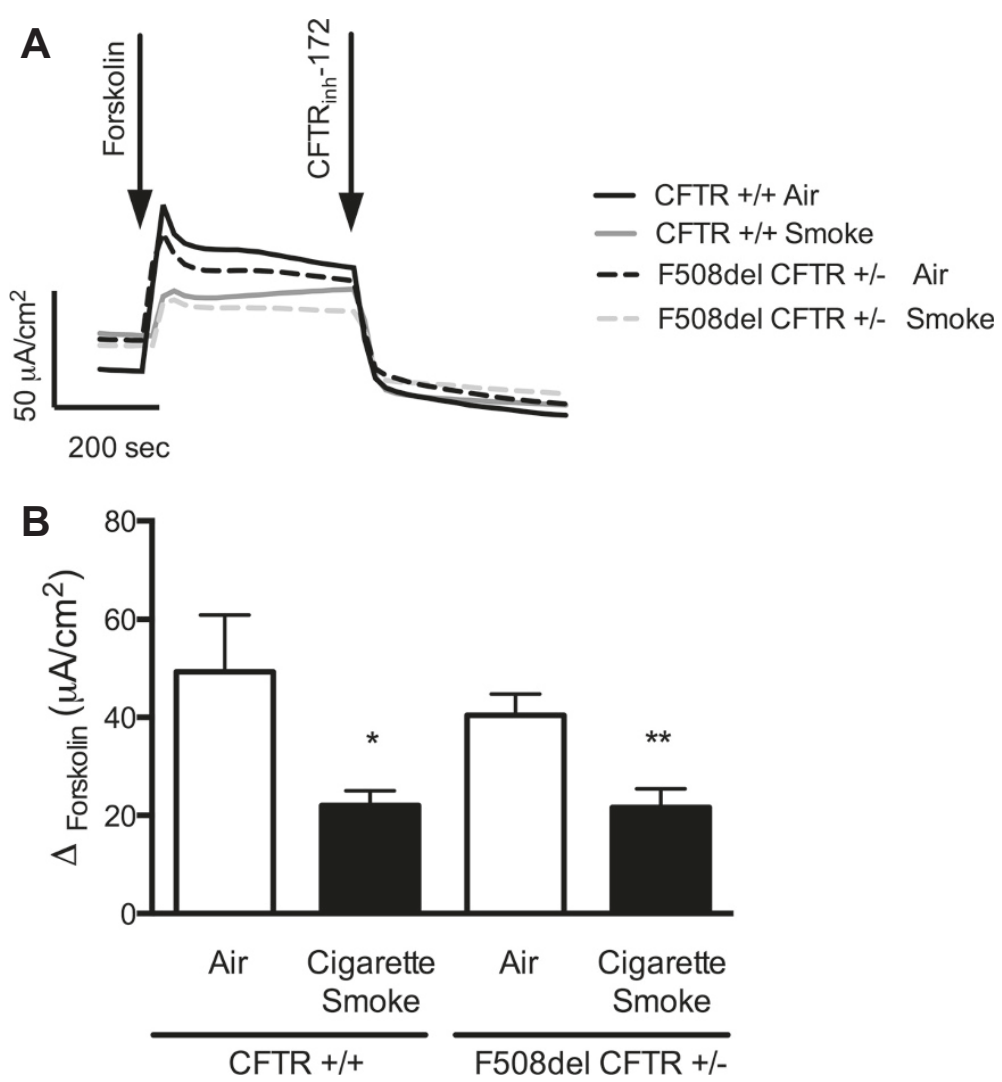

Figure 1 Effect of CFTR mutation heterozygosity on smoke-induced CFTR dysfunction in vitro. Well differentiated primary human bronchial epithelial cells (HBE) cells were isolated from healthy non-smokers and non-CF individuals and expressing either wild type CFTR $(C F T R+/+)$ or heterozygous F508del CFTR mutation (CFTR +/-). These cells were exposed to cigarette smoke generated from 1 cigarette for 10 min and CFTR function measured in Ussing chambers under voltage clamp conditions. A) Representative tracings of forskolin stimulated CFTR ion transport in HBE cells in vitro. Addition of forskolin $(20 \mu \mathrm{M})$ and CFTR $\mathrm{inh}_{172}(10 \mu \mathrm{M})$ are indicated. B) Forskolin-stimulated CFTR-dependent anion transport is summarized, $\mathrm{N}=6-8{ }^{*} \mathrm{P}<0.05,{ }^{* *} \mathrm{P}<0.005$. 

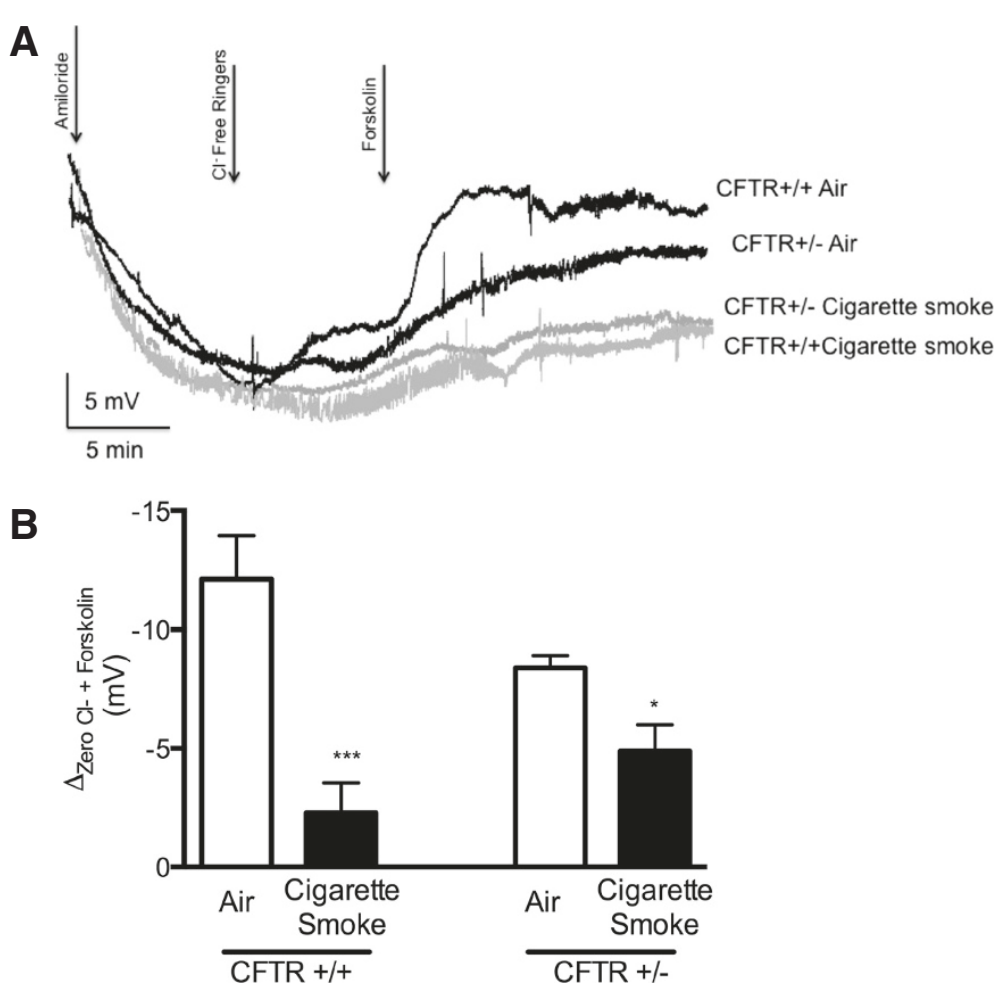

Figure 2 Effect of CFTR mutation heterozygosity on smoke-induced CFTR dysfunction in vivo. C57BL/6 J mice expressing wild type CFTR (CFTR $+/+$ ) or heterozygous CFTR (CFTR +/-) were exposed to whole cigarette smoke (4 cigarettes, twice daily) or room air control in whole body chambers for 2 weeks prior to CFTR functional estimation with nasal potential difference (NPD). A) Representative tracings of NPD measured in CFTR +/+ or CFTR +/- mice exposed to either cigarette smoke or air control. Initiation of amiloride (100 $\mu \mathrm{M})$, $\mathrm{Cl}^{-}$free ringers and $\mathrm{Cl}^{-}$free ringers plus forskolin $(20 \mu \mathrm{M})$ are indicated. B) Mean forskolin stimulated change in nasal potential difference, an indicator of CFTR mediated $\mathrm{Cl}^{-}$transport. $\mathrm{N}=8$ /condition, ${ }^{*} \mathrm{P}<0.05,{ }^{*} \mathrm{P}<0.005$.

Although the absolute reduction in CFTR activity was less prominent in heterozygous mice, the residual cAMP dependent CFTR activity in CFTR $(+/+)$ and CFTR (+/-) mice following WCS exposure were no different and favored heterozygous animals $(-0.99 \pm 2.07 \mathrm{mV}$ in CFTR $(+/+)$ vs. $-4.57 \pm 2.05 \mathrm{mV}$ in CFTR $(+/-), \mathrm{P}=0.26)$. Analysis of short-circuit current of excised trachea demonstrated a similar trend, with reduced CFTR dependent ion transport observed in both wild type and heterozygous trachea following WCS exposure that was not meaningfully different (Figure 3). The lack of statistically significant reduction in trachea CFTR activity following a 2-week exposure to WCS is consistent with previously reported data since this tissue exhibits time-dependent decrements [19]. Taken together, these data provide evidence that heterozygosity imposed by the presence of one CFTR mutation does not increase the susceptibility or magnitude of CFTR dysfunction following cigarette smoke exposure.

\section{Prevalence of CFTR mutations in patients with COPD and chronic bronchitis}

The lack of the expected increase in susceptibility to cigarette smoke induced CFTR dysfunction due to the

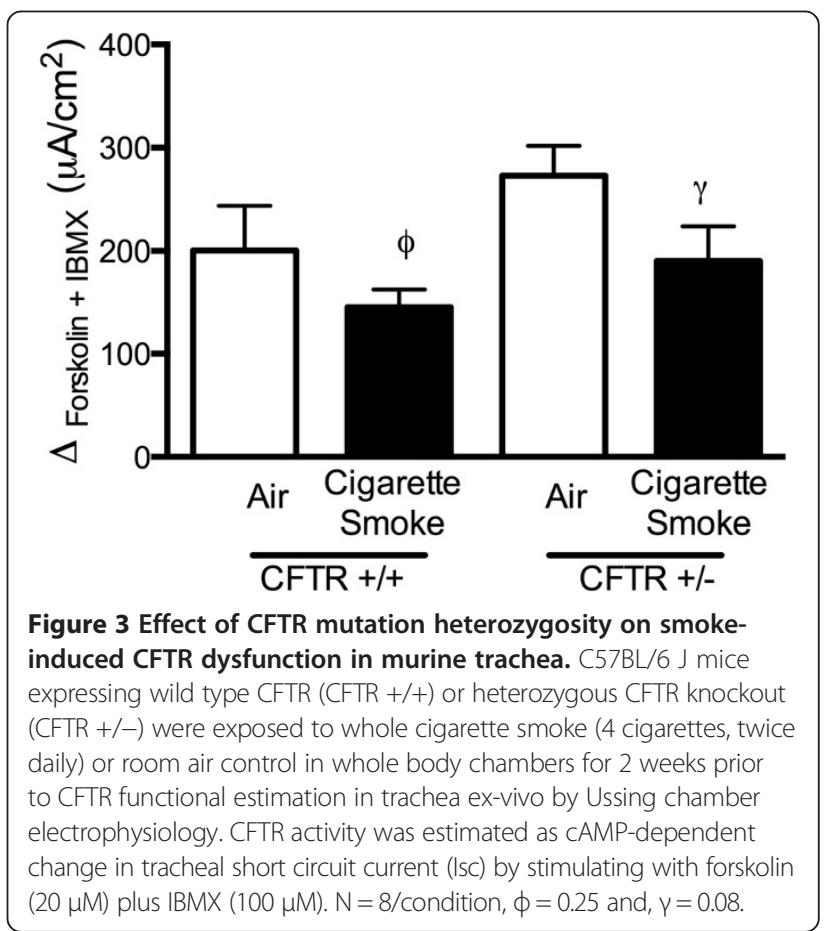


absence of one copy of CFTR prompted us to determine the prevalence of CFTR mutations among COPD patients with chronic bronchitis in comparison to the general Caucasian population. We evaluated 127 individuals with COPD and chronic bronchitis who participated in the Azithromycin in COPD Study sponsored by the COPD Clinical Research Network [37]. To enrich the population for those likely to exhibit CFTR abnormality, and assure best matching with our control group, we restricted the analysis to individuals with COPD, chronic bronchitis and of Caucasian descent. As shown in Table 2, the population had a slight male predominance, and $25 \%$ were current smokers. The mean $\mathrm{FEV}_{1} \%$ predicted reflected a moderate to severely ill population. There was a high frequency of health care utilization for respiratory symptoms and pulmonary exacerbations. Five of the 127 subjects (3.9\%) had detectable CFTR mutations based on a genetic panel containing 89 mutations. The frequency of CFTR mutations among those with COPD and chronic bronchitis was no different than the mutation rate seen in the control population (1356 of 32900, 4.1\%; P = NS; Table 3). Limiting the analysis to the F508del CFTR mutation, only 2 (1.5\%) of cases were positive, which was again no different than controls (2.7\%; P = NS).

\section{Discussion}

A number of studies have shown that cigarette smoke causes acquired CFTR dysfunction in smokers with and without COPD [14,15,17,19,30,38]. Here, we evaluated the effect CFTR heterozygosity on this pathway using in vitro and in vivo models of smoke exposure. As expected, cigarette smoke exposure reduced CFTR function in mice and cells, consistent with prior literature $[25,26]$. However, CFTR heterozygosity did not cause a functional disadvantage in either mice or primary human epithelia. At baseline mice and cells with CFTR (+/-) expression had slightly lower ion transport function

Table 2 Characteristics of COPD study subjects undergoing CFTR genetic analysis

\begin{tabular}{ll}
\hline Characteristics & 62 \\
\hline Age (years) & 65.5 \\
Male (\%) & 25 \\
Current smokers (\%) & 64 \\
Average pack/years & 48 \\
Hospitalizations or emergency department visits for respiratory & \\
symptoms in the previous year (\%) & 41 \\
Required antibiotics for chest infections in previous 3 months (\%) & 37 \\
Required oral steroids for respiratory symptoms in previous & \\
3 months (\%) & 36 \\
Average FEV 1 (\% predicted) & \\
\hline
\end{tabular}

$\mathrm{FEV}_{1}$ - Forced Expiratory Volume in one second.
Table 3 Prevalence of CFTR mutations in Caucasian COPD and control subjects

\begin{tabular}{lccc}
\hline Study population & With mutation & Without mutation & P Value \\
\hline COPD N=127 & & & \\
Any mutation & $5(3.9 \%)$ & $122(96.1 \%)$ & 0.92 \\
F508del & $2(1.5 \%)$ & $125(98.5 \%)$ & 0.63 \\
$\quad$ Non-F508del & $3(2.4 \%)$ & $124(97.6 \%)$ & 0.63 \\
Controls N = 32,900 & & & \\
Any mutation & $1,356(4.1 \%)$ & $31,544(95.9 \%)$ & \\
F508del & $880(2.7 \%)$ & $32,020(97.3 \%)$ & \\
Non-F508del & $476(1.4 \%)$ & $32,424(98.6 \%)$ & \\
\hline
\end{tabular}

P-values presented are Chi-square analyses compared to general Caucasian population.

compared to their wild type controls ( $90 \%$ of WT). However, following smoke exposure, each reached similar levels $(\sim 40 \%$ of WT). Hence, the presence of a protective 2nd normal CFTR allele was not sufficient to overcome the functional decrement caused by smoke. These data we provide the first experimental evidence that acquired CFTR dysfunction from environmental exposure to cigarette smoke or other COPD related pathology is the principle contributor to the defective ion transport phenotype $[15,19]$ and is not substantially affected by the presence of CFTR mutation heterozygosity. The degree of CFTR decrement observed following smoke exposure and due to CFTR mutation heterozygosity alone were each consistent with prior reports in carriers [33], smokers [14,15], cells [17,30,36], and mice [19] exposed to cigarette smoke and CF, lending further confidence to our findings.

To confirm findings in the laboratory, we also investigated whether genetic heterozygosity for CFTR mutations contributes to the prevalence of COPD with chronic bronchitis in cigarette smokers. We found that CFTR mutations are not more frequent in COPD patients with moderate to severe obstruction and chronic bronchitis symptoms compared to a control population of Caucasian individuals. Despite clear evidence that cigarette smoke reduces CFTR mediated anion transport, these results suggest that congenital CFTR mutations do not contribute to a genetic predisposition to the prevalence of COPD and chronic bronchitis. Further, our in vitro and in vivo data provide an explanation for the absence of enhanced susceptibility to cigarette smoke induced chronic bronchitis in individuals heterozygous for CFTR mutations.

Unlike Gervais et al., we did not demonstrate an increased association in the F508del CFTR allele and chronic bronchitis, however this study observed the association in individuals with elevated sweat chloride in an era before comprehensive CFTR genetic analysis, potentially resulting in the inclusion of patients with a mild 
form of cystic fibrosis due to two unrecognized CFTR mutations; smoking related COPD was also not specified in this report [21]. Our findings also contrast to Kostuch et al. who reported a slight increase (5 out of 32 ) in incidence of F508del mutations in chronic bronchitis patients in Poland. Although the authors attempted to enrich subjects for chronic bronchitis, the criterion used in that study was based on persistent chronic effective cough alone, and did not include any other clinical parameters such as a history of smoking. Similarly, we did not observe any increase in the incidence of M470V or R75Q as reported earlier in COPD patients from Serbia $[22,23]$. These studies were based on small subject groups $(<20)$ and were based on limited clinical phenotyping. Further, the M470V polymorphism is no longer thought to contribute to CF disease [39]. Differences in the baseline prevalence of these less common CFTR mutations due to genetic founder effects may also have contributed to the disparate results. Despite these distinctions, the conclusion reported in this manuscript are based on a more complete clinical evaluation and are in agreement with conclusions drawn from large unbiased genetic approaches, including recent GWAS analyses, where no apparent increase in CFTR mutations was observed [40].

The lack of an association with the prevalence of chronic bronchitis stand in contrast to studies in asthma where in a Swedish cohort of asthmatics, F508del CFTR heterozygosity was significantly more prevalent when compared to the control population. Further, asthmatic individuals heterozygous for CFTR had decreased pulmonary function and airway obstruction in comparison to those without mutant CFTR alleles [41]. Similarly, CFTR mutations have been reported in increased frequency among patients with non-CF chronic rhinosinusitis [35]. This may be due to differences in the biology of COPD as compared to these disorders, or the size of our study.

Our study has important limitations. Since, our analyses were focused on one sub-phenotype of COPD (i.e. chronic bronchitis), it would be beneficial to conduct additional CFTR genetic analysis in a larger cohort of subjects to rule out CFTR as a contributor. For example, there are over 1900 potential disease-causing mutations in CFTR [42] and our analysis was limited to the top 89. Even though our analyses included $88 \%$ of alleles found in Caucasians, CFTR sequencing may detect an association not identified by our analyses. Furthermore, the same principle could reduce the sensitivity of GWAS analyses intended to detect an association with CFTR mutations, since SNPs could be spread over many locations along the CFTR gene, depending on the allele. Our study was performed in a modest sized cohort and would be strengthened by a targeted approach in a much larger sample. CFTR genetics could also influence the severity of the disease, rather than prevalence, and was not assessed by this analysis. While our animal studies recapitulated that observed humans, they are not useful to evaluate chronic bronchitis, since neither mice deficient in the CF gene or chronically exposed to cigarette smoke develop mucus obstruction or retention. Larger animal models may be needed for studies of this sort.

\section{Conclusion}

In total, the experimental data indicate why smokers with CFTR mutations may not exhibit a genetic predisposition to develop chronic bronchitis or a gene dose effect, even if chronic bronchitis symptoms are partially mediated by abnormal CFTR function. Our data suggest that effects of cigarette smoke on CFTR function acquired by environmental exposure are far more influential to clinical phenotype than inherited defects due to mutations in CFTR. These results may inform appropriate patient selection for trials evaluating CFTR modulators or ion channel agonists for the treatment of COPD $[14,30]$.

\section{Abbreviations \\ CAMP: Cyclic adenosine monophosphate; CF: Cystic fibrosis; CFTR: Cystic fibrosis transmembrane conductance regulator; COPD: Chronic obstructive pulmonary disease; WCS: Whole cigarette smoke; CSE: Cigarette smoke extract; HBE: Human bronchial epithelial; GWAS: Genome wide association studies; Isc: Short circuit current; LAPD: Lower airway potential difference; NPD: Nasal potential difference; TER: Transepithelial electrical resistance; WT: Wild type.}

\section{Competing interests}

S.M.R served as PI for CF Clinical Trials sponsored by Vertex Pharmaceuticals and Novartis. He has received COPD-related grant funding from NHLBI and Forest Research Institute. M.T.D has served on COPD-related advisory boards for Ikaria, Forest, GlaxoSmithKline and Boehringer Ingelheim. He has served as site PI for contracted COPD clinical trials sponsored by Aeris, Centocor, Pfizer, Otsuka, Pulmonx, GlaxoSmithKline and Boehringer Ingelheim. He has received COPDrelated grant funding from Forest, GlaxoSmithKline and NHLBI.

\section{Authors' contributions}

SVR, JHT, MTD, and SMR conceived of the experiments; SVR, JHT, and SKGP, conducted the research; SVR, JHT, RO, PF, MTD, MTD, and SMR analyzed the data; SVR and SMR wrote the manuscript; SMR and MTD supervised the project. All authors read and approve the final manuscript.

\section{Acknowledgements}

The authors acknowledge the NIH COPD Clinical Research Network for providing DNA for CFTR genetic testing and associated clinical data (Grant \# U10HL074424). The authors thank Dr. Eric J. Sorscher for infrastructural support. The authors also acknowledge Ms. Marina Mazur, Ms. Arianne Fulce, Ms. Kathy Sexton, Mr. Thurman Richardson and the Tissue Collection and Banking Facility at UAB for services related to airway tissue procurement; and the UAB Center for Clinical and Translational Science for infrastructural support. The authors acknowledge the efforts of Ming Du and David Bedwell for supplying mice through the UAB CF Center Animal Core. We also acknowledge the assistance of Jeremy $A$ Boydston and John $E$ Trombley of Southern Research Institute for cigarette smoke exposure analysis.

\section{Funding}

This research is sponsored by the NIH (R01 HL105487 to S.M.R., P30 DK072482 to the UAB CF Research Center, 5UL1 RR025777 and U10HL074424) and the Cystic Fibrosis Foundation (CLANCY09YO to S.M.R. and R464-CF). S.V.R. is supported by American Lung Association Senior Research Fellowship (RT-219427-N). The funders had no role in study design, data collection and analysis, decision to publish, or preparation of the manuscript. 


\section{Author details}

${ }^{1}$ Department of Medicine, University of Alabama at Birmingham, MCLM 706 1918 University Blvd., Birmingham, AL, USA. ²Department of Pediatrics, University of Alabama at Birmingham, Birmingham, AL, USA. ${ }^{3}$ Departments of Cell Developmental and Integrative Biology, University of Alabama at Birmingham, Birmingham, AL, USA. ${ }^{4}$ The Gregory Fleming James Cystic Fibrosis Research Center, University of Alabama at Birmingham, Birmingham, AL, USA. ${ }^{5}$ UAB Lung Health Center, University of Alabama at Birmingham, Birmingham, AL, USA. ${ }^{6}$ Medical Genetics Laboratories, Baylor College of Medicine, Houston, TX, USA

Received: 25 December 2013 Accepted: 2 February 2014

Published: 11 February 2014

\section{References}

1. Minino AM, Murphy SL, Xu J, Kochanek KD: Deaths: final data for 2008. Natl Vital Stat Rep 2011, 59:1-126.

2. Fahy JV, Dickey BF: Airway mucus function and dysfunction. N Engl J Med 2010, 363:2233-2247.

3. Dahl M, Tybjaerg-Hansen A, Lange P, Vestbo J, Nordestgaard BG: Change in lung function and morbidity from chronic obstructive pulmonary disease in alpha1-antitrypsin MZ heterozygotes: a longitudinal study of the general population. Ann Intern Med 2002, 136:270-279.

4. Sandford AJ, Weir TD, Spinelli JJ, Pare PD: Z and S mutations of the alpha1-antitrypsin gene and the risk of chronic obstructive pulmonary disease. Am J Respir Cell Mol Biol 1999, 20:287-291.

5. Vestbo J, Anderson W, Coxson HO, Crim C, Dawber F, Edwards L, Hagan G, Knobil K, Lomas DA, MacNee W, et al: Evaluation of COPD Longitudinally to Identify Predictive Surrogate End-points (ECLIPSE). Eur Respir J 2008, 31:869-873.

6. Kim DK, Cho MH, Hersh CP, Lomas DA, Miller BE, Kong X, Bakke P, Gulsvik A, Agusti A, Wouters E, et al: Genome-wide association analysis of blood biomarkers in chronic obstructive pulmonary disease. Am J Respir Crit Care Med 2012, 186:1238-1247.

7. Varga K, Goldstein RF, Jurkuvenaite A, Chen L, Matalon S, Sorscher EJ, Bebok Z, Collawn JF: Enhanced cell-surface stability of rescued DeltaF508 cystic fibrosis transmembrane conductance regulator (CFTR) by pharmacological chaperones. Biochem J 2008, 410:555-564.

8. Houghton AM, Quintero PA, Perkins DL, Kobayashi DK, Kelley DG, Marconcini LA, Mecham RP, Senior RM, Shapiro SD: Elastin fragments drive disease progression in a murine model of emphysema. J Clin Invest 2006, 116:753-759.

9. Cystic Fibrosis Foundation C: Cystic Fibrosis Patient Registry. 2012.

10. Sharer N, Schwarz M, Malone G, Howarth A, Painter J, Super M, Braganza J: Mutations of the cystic fibrosis gene in patients with chronic pancreatitis. N Engl J Med 1998, 339:645-652.

11. Cohn JA, Friedman KJ, Noone PG, Knowles MR, Silverman LM, Jowell PS: Relation between mutations of the cystic fibrosis gene and idiopathic pancreatitis. N Engl J Med 1998, 339:653-658.

12. Chillon M, Casals T, Mercier B, Bassas L, Lissens W, Silber S, Romey MC, Ruiz-Romero J, Verlingue C, Claustres $M$, et al: Mutations in the cystic fibrosis gene in patients with congenital absence of the vas deferens. N Engl J Med 1995, 332:1475-1480.

13. Miller PW, Hamosh A, Macek M Jr, Greenberger PA, MacLean J, Walden SM, Slavin RG, Cutting GR: Cystic fibrosis transmembrane conductance regulator (CFTR) gene mutations in allergic bronchopulmonary aspergillosis. Am J Hum Genet 1996, 59:45-51.

14. Sloane PA, Shastry S, Wilhelm A, Courville C, Tang LP, Backer K, Levin E, Raju SV, Li Y, Mazur M, et al: A pharmacologic approach to acquired cystic fibrosis transmembrane conductance regulator dysfunction in smoking related lung disease. PLoS One 2012, 7:e39809

15. Dransfield MT, Wilhelm AM, Flanagan B, Courville C, Tidwell SL, Raju SV, Gaggar A, Steele C, Tang LP, Liu B, Rowe SM: Acquired Cystic Fibrosis Transmembrane Conductance Regulator Dysfunction in the Lower Airways in COPD. Chest 2013, 144:498-506.

16. Cantin AM, Hanrahan JW, Bilodeau G, Ellis L, Dupuis A, Liao J, Zielenski J, Durie P: Cystic fibrosis transmembrane conductance regulator function is suppressed in cigarette smokers. Am J Respir Crit Care Med 2006, 173:1139-1144.

17. Clunes LA, Davies CM, Coakley RD, Aleksandrov AA, Henderson AG, Zeman KL, Worthington EN, Gentzsch M, Kreda SM, Cholon D, et al: Cigarette smoke exposure induces CFTR internalization and insolubility, leading to airway surface liquid dehydration. FASEB J 2012, 26:533-545.
18. Stanley PJ, Wilson R, Greenstone MA, MacWilliam L, Cole PJ: Effect of cigarette smoking on nasal mucociliary clearance and ciliary beat frequency. Thorax 1986, 41:519-523.

19. Raju SV, Jackson PL, Courville CA, McNicholas CM, Sloane PA, Sabbatini G, Tidwell S, Tang LP, Liu B, Fortenberry JA, et al: Cigarette smoke induces systemic defects in cystic fibrosis transmembrane conductance regulator function. Am J Respir Crit Care Med 2013, 188:1321-1330.

20. Stockley RA: Bronchiectasis with chronic obstructive pulmonary disease: association or a further phenotype? Am J Respir Crit Care Med 2013, 187:786-788.

21. Gervais R, Lafitte J-J, Dumur V, Kesteloot M, Lalau G, Houdret N, Roussel P: Sweat chloride and CFîF508 mutation in chronic bronchitis or bronchiectasis. Lancet 1993, 342:997.

22. Divac A, Nikolic A, Mitic-Milikic M, Nagorni-Obradovic L, Petrovic-Stanojevic N, Dopudja-Pantic V, Nadaskic R, Savic A, Radojkovic D: High frequency of the R75Q CFTR variation in patients with chronic obstructive pulmonary disease. J Cyst Fibros 2004, 3:189-191.

23. Stankovic M, Nikolic A, Divac A, Tomovic A, Petrovic-Stanojevic N, Andjelic M, Dopudja-Pantic V, Surlan M, Vujicic I, Ponomarev D, et al: The CFTR M470V gene variant as a potential modifier of COPD severity: study of Serbian population. Genet Test 2008, 12:357-362.

24. Kostuch M, Semczuk A, Szarewicz-Adamczyk W, Gasowska-Giszczak U, Wojcierowski J, Kulczycki L: Detection of CFTR gene mutations in patients suffering from chronic bronchitis. Arch Med Res 2000, 31:97-100.

25. Entzian P, Muller E, Boysen A, Artlich A, Schwinger E, Schlaak M: Frequency of common cystic fibrosis gene mutations in chronic bronchitis patients. Scand J Clin Lab Invest 1995, 55:263-266.

26. Artlich A, Boysen A, Bunge S, Entzian P, Schlaak M, Schwinger E: Common CFTR mutations are not likely to predispose to chronic bronchitis in northern Germany. Hum Genet 1995, 95:226-228.

27. Akai S, Okayama H, Shimura S, Tanno Y, Sasaki H, Takishima T: Delta F508 mutation of cystic fibrosis gene is not found in chronic bronchitis with severe obstruction in Japan. Am Rev Respir Dis 1992, 146:781-783.

28. Van Goor F, Hadida S, Grootenhuis PD, Burton B, Cao D, Neuberger T, Turnbull A, Singh A, Joubran J, Hazlewood A, et al: Rescue of CF airway epithelial cell function in vitro by a CFTR potentiator, VX-770. Proc Natl Acad Sci U S A 2009, 106:18825-18830.

29. Pyle LC, Ehrhardt A, Mitchell LH, Fan L, Ren A, Naren AP, Li Y, Clancy JP, Bolger GB, Sorscher EJ, Rowe SM: Regulatory domain phosphorylation to distinguish the mechanistic basis underlying acute CFTR modulators. Am J Physiol Lung Cell Mol Physiol 2011, 301:L587-L597.

30. Lambert JA, Raju SV, Tang LP, McNicholas-Bevensee C, Li Y, Clifford CA Dransfield MT, Bolger GB, Rowe S, Lambert JA, Raju SV, Tang LP, McNicholas-Bevensee C, Li Y, Clifford CA, Dransfield MT, Bolger GB, Rowe SM: CFTR activation by roflumilast contributes to therapeutic benefit in chronic bronchitis. Am J Respir Cell Mol Biol 2013: [Epub ahead of print].

31. Rowe SM, Sloane P, Tang LP, Backer K, Mazur M, Buckley-Lanier J, Nudelman I, Belakhov V, Bebok Z, Schwiebert E, et al: Suppression of CFTR premature termination codons and rescue of CFTR protein and function by the synthetic aminoglycoside NB54. J Mol Med 2011:

32. Albert RK, Connett J, Bailey WC, Casaburi R, Cooper JA Jr, Criner GJ, Curtis $J$, Dransfield MT, Han MK, Lazarus SC, et al: Azithromycin for prevention of exacerbations of COPD. N Engl J Med 2011, 365:689-698.

33. Wilschanski M, Dupuis A, Ellis L, Jarvi K, Zielenski J, Tullis E, Martin S, Corey $M$, Tsui LC, Durie P: Mutations in the cystic fibrosis transmembrane regulator gene and in vivo transepithelial potentials. Am J Respir Crit Care Med 2006, 174:787-794.

34. Savitski AN, Mesaros C, Blair IA, Cohen NA, Kreindler JL: Secondhand smoke inhibits both $\mathrm{Cl}$ - and $\mathrm{K}+$ conductances in normal human bronchial epithelial cells. Respir Res 2009, 10:120.

35. Wang X, Moylan B, Leopold DA, Kim J, Rubenstein RC, Togias A, Proud D, Zeitlin PL, Cutting GR: Mutation in the gene responsible for cystic fibrosis and predisposition to chronic rhinosinusitis in the general population. JAMA 2000, 284:1814-1819.

36. Kreindler JL, Jackson AD, Kemp PA, Bridges RJ, Danahay $\mathrm{H}$ : Inhibition of chloride secretion in human bronchial epithelial cells by cigarette smoke extract. Am J Physiol Lung Cell Mol Physiol 2005, 288:L894-L902.

37. Tidwell SL, Westfall E, Dransfield MT: Lung volume reduction for advanced emphysema: surgical and bronchoscopic approaches. South Med J 2012, 105:56-61

38. Cantin AM: Cellular response to cigarette smoke and oxidants: adapting to survive. Proc Am Thorac Soc 2010, 7:368-375. 
39. Bombieri C, Giorgi S, Carles S, de Cid R, Belpinati F, Tandoi C, Pallares-Ruiz N, Lazaro C, Ciminelli BM, Romey MC, et al: A new approach for identifying non-pathogenic mutations. An analysis of the cystic fibrosis transmembrane regulator gene in normal individuals. Hum Genet 2000, 106:172-178.

40. Berndt A, Leme AS, Shapiro SD: Emerging genetics of COPD. EMBO Mol Med 2012, 4:1144-1155.

41. Dahl M, Nordestgaard BG, Lange $P$, Tybjaerg-Hansen A: Fifteen-year follow-up of pulmonary function in individuals heterozygous for the cystic fibrosis phenylalanine-508 deletion. J Allergy Clin Immunol 2001, 107:818-823.

42. Ferec C, Cutting GR: Assessing the disease-liability of mutations in CFTR. Cold Spring Harb Perspect Med 2012, 2:a009480.

doi:10.1186/1465-9921-15-18

Cite this article as: Raju et al:: Impact of heterozygote CFTR Mutations in COPD patients with Chronic Bronchitis. Respiratory Research 2014 15:18.

\section{Submit your next manuscript to BioMed Central and take full advantage of:}

- Convenient online submission

- Thorough peer review

- No space constraints or color figure charges

- Immediate publication on acceptance

- Inclusion in PubMed, CAS, Scopus and Google Scholar

- Research which is freely available for redistribution 